\title{
A construção de conhecimento de professores da Educação de Jovens e Adultos/Fase I pela formação continuada em Ciências
}

\author{
Jaqueline Miliavaca Wielewski
}

Dulce Maria Strieder

\section{Resumo}

O artigo visa abordar caminhos para a construção do conhecimento profissional do professor da Educação de Jovens e Adultos (EJA)/Fase I, com o auxílio da formação continuada em Ciências. No contexto da EJA, a formação continuada, em geral, tem uma função ampliada devido à carência de estruturação de conhecimentos sobre a modalidade nos cursos de formação inicial dos professores. Na especificidade da atuação na fase I da EJA, ainda que ela seja direcionada para o processo de alfabetização, há que se considerar que este aluno não pode ser visto como atrasado, e as metodologias devem evitar uma infantilização. No tocante à alfabetização, sua conceituação deve ultrapassar os limites da leitura e escrita e imergir em um panorama mais amplo de alfabetização científica. A pesquisa que dá origem à estruturação deste texto é de ordem qualitativa e os dados, coletados via entrevista áudio-gravada junto a 18 professores da EJA, trazem a percepção destes acerca da Formação Continuada em Ciências vivenciada. Os dados indicam a carência destes momentos de formação, a inadequação destes ao contexto da EJA e o afastamento do cotidiano da sala de aula e pouco ampara os profissionais em termos epistemológicos e didáticopedagógicos.

Palavras-chave: Educação Científica, EJA, Formação de Professores. 


\title{
The knowledge background of teachers of youth and Adult Education/Phase I with continuing education support in Sciences
}

\author{
Jaqueline Miliavaca Wielewski
}

Dulce Maria Strieder

\section{Abstract}

The paper aims at addressing some possibilities to help on the professional knowledge background of a teacher of Youth and Adult Education/Phase I, with continuing education support in Sciences. According to the Youth and Adult Education context, continuing education, in general, has an expanded role due to the lack of knowledge structuring about modality in the initial teacher training courses. But, regarding specificity of performance in phase I of Youth and Adult Education, although it is directed to the literacy process, it is necessary to consider that this student cannot be seen as a slow one, and the methodologies must avoid infantilization. With regard to literacy, its conceptualization must go beyond the limits of reading and writing and immerse itself in a broader picture of scientific literacy. Thus, this research begins the structuring of this text and has a qualitative nature, and data were collected by an audio-taped interview with 18 Youth and Adult Education teachers. So, they show their perception about Continued Science Education. The data have evinced the lack of these training moments, their inadequacy concerning Youth and Adult Education context and the distance from the classroom, little supporting the professionals in epistemological and didactic-pedagogical terms.

Keywords: Scientific Education, Young and Adult Education, Teacher Training Continuing. 


\title{
Introdução
}

A Formação Continuada é uma das necessidades mais importantes para os professores, visto que a Formação Inicial não proporciona embasamento teórico-prático suficiente para o desempenho do profissional (BONZANINI; BASTOS, 2009). E, ainda que fornecesse, a constante reflexão sobre a prática em associação aos fundamentos teóricos é essencial. Resolver questões que surgem em sala de aula, tomar decisões coerentes quanto ao conteúdo e às práticas pedagógicas utilizadas são os maiores desafios da Formação Continuada.

A modalidade EJA foi banalizada por muitos anos, como ressaltam Soares e Pedroso (2016). Havia a visão de que qualquer um poderia ensinar os jovens e adultos. O improviso imperou por muito tempo em relação à EJA, assim também a Formação Continuada foi esquecida, embora todos os anos a modalidade recrute centenas de jovens e adultos para a conclusão da educação básica. Em se tratando do ensino de Ciências, Krasilchik (1987) explicita que é comum relacionar a má qualidade do ensino de Ciências com a frágil formação do educador:

\begin{abstract}
Os cursos de licenciatura têm sido objeto de críticas em relação a sua possibilidade de preparar docentes, tornando-os capazes de ministrar bons cursos, de acordo com as concepções do que aspiram por uma formação para o ensino de Ciências; possuem deficiências nas áreas metodológicas que se ampliaram para o conhecimento das próprias disciplinas, levando à insegurança em relação à classe, à baixa qualidade das aulas [...] (KRASILCHIK, 1987, p. 47).
\end{abstract}

Giovinazzo (2017) e Gatti (2010) relatam que, em 2006, o MEC determinou a Pedagogia como licenciatura, organizou o curso para formar professores da Educação Infantil e das séries iniciais, alterou seu foco a fim de que o curso fosse direcionado para a Formação de gestores. Atualmente, os professores que atuam nas turmas de Educação de Jovens e Adultos (EJA) do Ensino Fundamental - Fase I (primeiro ao quarto período), na sua maioria, possuem formação em Pedagogia conforme especificação da LDB 9694/96, e são responsáveis por todas as disciplinas ofertadas.

Inserindo-se neste panorama, o artigo tem por objetivo analisar os relatos dos professores que atuam com a EJA - Fase I, principalmente sobre a formação continuada de Ciências ofertada pela Secretaria Municipal de Educação (SEMED) da cidade de Cascavel. Os relatos dos docentes foram coletados via entrevistas realizadas com todos os professores regentes e atuantes na EJA Fase I no Município de Cascavel, com total de 18 participantes. A entrevista continha questões relacionadas à Formação Continuada e ao ensino de Ciências.

As entrevistas foram analisadas a fim de se obter o caráter qualitativo que se caracteriza "[...] no reconhecimento e na análise de diferentes perspectivas; nas reflexões dos pesquisadores a respeito de suas pesquisas como parte do processo de produção de conhecimento; e nas variedades de abordagens e métodos" (FLICK, 2009, p. 22). 
É possível realizar uma análise sobre a forma como a Formação Continuada pode contribuir para o desenvolvimento do conhecimento do professor a partir da abordagem qualitativa. Flick (2009) ainda destaca que a abordagem qualitativa enaltece algumas questões fundamentais para o encaminhamento da pesquisa, como a "apropriabilidade de métodos e teorias, perspectivas dos participantes e sua diversidade; reflexividade do pesquisador e da pesquisa, variedade de abordagens e de métodos na pesquisa” (p. 23).

Assim, o artigo busca traçar a relação da Formação Continuada do Pedagogo atuante na EJA - Fase I, com o ensino de Ciências, visto que o profissional dessa área necessita de constante crescimento intelectual para lidar com os variados desafios do cotidiano de sala de aula.

\section{A FORMAÇÃO DO PROFESSOR E A CONSTRUÇÃO DO CONHECIMENTO}

O curso de Pedagogia é o lugar de formação de professores que atuarão na Educação Infantil, no Ensino Fundamental I e na EJA (GIOVINAZZO, 2017). Entretanto, o mesmo autor destaca que nas Diretrizes Curriculares para o curso de Pedagogia no Brasil, ainda, prevalece a formação técnica e não há uma proposta capaz de articular a Educação com a Formação docente e a Política.

Conforme Gatti (2010), também existe um pequeno percentual de carga horária para discussão da Educação de Jovens e Adultos nos cursos de licenciatura em pedagogia.

Poucos cursos de licenciatura em Pedagogia propõem disciplinas que permitam algum aprofundamento e formação de competências na área de educação infantil, e menos ainda em relação a modalidades educacionais (EJA e educação especial), seja mediante a oferta de optativas, seja de tópicos e projetos especiais (GATTI, 2010, p. 151).

A formação do professor da EJA deve ser específica e acrescer elementos diferenciados das demais modalidades. Os cursos de Pedagogia com encaminhamentos diferenciados para a EJA são uma novidade, como relatam Maraschin e Bellhochio (2006, p. 2). "É muito recente a criação de cursos de Pedagogia com ênfase na EJA ou que ofereçam disciplinas que contemplem discussões sobre o ensino e a aprendizagem do aluno jovem e do aluno adulto". As autoras ainda observam que devido ao fato dos cursos de Pedagogia terem pouca discussão sobre a EJA, a Formação continuada pode possibilitar ao professor uma participação dinâmica, uma formação para desenvolver a autonomia deste profissional.

Na Resolução CNE/CP No 1/2006 que institui as Diretrizes Curriculares Nacionais para o Curso de Graduação em Pedagogia, está descrito no art. $5^{\circ}$ o que se espera do futuro professor após o término da graduação. Os incisos que vão de I a XVI descrevem que o professor deve: atuar com ética e compromisso em busca de uma sociedade igualitária; cuidar e educar crianças de zero a cinco anos, a fim de garantir o desenvolvimento integral do aluno; 
ensinar de maneira interdisciplinar; ter postura investigativa e integrativa; respeitar diferenças; saber utilizar instrumentos pedagógicos; entre outras atuações (BRASIL, 2006).

Tal expectativa gerada em torno dos profissionais, a partir do documento do MEC, pode provocar receios no professor em formação devido ao compromisso a ele imposto e à realidade em que está inserido. A “[...] qualidade do ensino, no que diz respeito ao profissional da educação, passa por uma articulação entre formação básica, condições de trabalho e formação continuada" (BONZANINI; BASTOS, 2009, p. 9).

Gatti (2009) ressalta que as especializações devem integrar cada vez mais o cotidiano, inclusive devido às mudanças nos conhecimentos e também às tecnologias significativas no desenvolvimento do trabalho. Nesse intento, as universidades podem contribuir para a Formação Continuada e a construção do conhecimento do professor.

Bastos (2017) compreende que os saberes mais importantes para a Formação de professores são aqueles que fornecem elementos para a prática real e diária dos docentes. Estes conhecimentos seriam estruturados em grupos de estudos orientados pelas universidades em forma de pesquisa acadêmica, com foco nas práticas de sala de aula, para organizar um acervo de conhecimentos acerca das Ciências. Entre os profissionais da educação básica, é comum ouvir afirmações que dizem que a universidade está muito longe da realidade escolar e que essa deveria oferecer mais contribuições; que a teoria abordada nestas universidades não tem qualquer ligação com a prática escolar e que unicamente a prática dará conta de formar o docente. Assim, tem-se a impressão equivocada de que a universidade e a escola trilham caminhos opostos.

Neste contexto, Bastos (2017) aponta que é preciso retomar uma questão fundamental, a de que a teoria com que a universidade trabalha fornece subsídios para a atuação do professor. A prática e a teoria devem caminhar entrelaçadas, de forma que uma complete a outra. Ainda fundamentado em Bastos (2017), é importante lembrar que muitos professores têm a visão de que somente a prática irá garantir a formação do professor. Porém, é inegável a relevância da teoria como suporte para as práticas pedagógicas e na Formação Continuada para a construção do conhecimento sobre a prática. Neste sentido, Gimenes (2011) esclarece: Entendemos que a teoria deva vir juntamente com a prática, tendo a prática com fundamento, finalidade e critério de verdade. Apenas a atividade teórica permite que a reflexão vá além da experiência imediata e dos círculos viciosos nos quais se encontra (GIMENES, 2011, p. 31).

É enriquecedora a união entre a pesquisa acadêmica, as Formações Continuadas e os conteúdos de Ciências, pois auxilia na resolução dos problemas de sala de aula, atrelados ao conhecimento, com estudos fundamentados em teorias epistêmicas e metodológicas. Assim, tais aspectos devem nortear o trabalho docente, sempre respeitando o desenvolvimento dos alunos. Para Bastos (2017), [...] a relação teoria-prática no trabalho do professor não pode mais 
ser entendida segundo a concepção da racionalidade técnica, tornando-se necessário que seja pensada em termos de conceitos como os de práxis e racionalidade crítica ou discursiva (BASTOS, 2017, p. 01).

É preciso repensar a relação estabelecida entre teoria e prática no contexto das formações continuadas para que essas contribuam para a construção do conhecimento do professor. Vale também considerar que o professor busca soluções para resolver as dificuldades inerentes à sala de aula, cuja compreensão não se resume à prática. Em termos de sua configuração, é importante que a Formação Continuada disponibilizada seja constituída não apenas por conteúdos soltos, mas que o conteúdo abarque questões epistemológicas que contribuam para a construção do conhecimento. É desafiadora a questão de colocar os conhecimentos que as universidades produzem ao alcance dos professores; para tanto, são necessários esforços, tanto dos professores quanto dos docentes pesquisadores universitários. Enfim, é possível perceber pequenos avanços quanto às limitações já citadas, porém, para uma abordagem mais aprofundada, é preciso entender como as políticas públicas interferem na Formação Continuada (BASTOS, 2017).

Pensando sobre as questões sociais, são necessárias políticas públicas para garantir condições de trabalho aos professores e nessas, as Formações Continuadas específicas são essenciais. Nas recentes décadas, no âmbito das políticas públicas, tem-se o financiamento da educação dado pelo Fundo de Manutenção e Desenvolvimento da Educação Básica e de Valorização dos Profissionais da Educação (FUNDEB), com vigência estabelecida para o período 2007-2020. É um fundo originado na arrecadação de impostos que garante o pagamento de um valor simbólico por aluno, com vistas ao financiamento da educação nos municípios, para o ensino Fundamental I e Educação de Jovens e Adultos (EJA) Fase I (BRASIL, 2017). Segundo Gatti (2009), “[...] há necessidade de continuidade nessas políticas, e não as interrupções sucessivas dessas iniciativas como temos assistido ao longo dos últimos 20 anos" (GATTI, 2009, p. 224).

No que tange à ampliação das responsabilidades atribuídas ao professor está a expectativa de que esse consiga dar conta de muitas questões, somente amparado pela Formação inicial, ignorando as variáveis que interferem como as atinentes às precárias condições de trabalho, que levam, muitas vezes, à mudança no foco de que a principal função do professor é promover e estimular o estudo dos conteúdos na busca por conhecimento.

\section{A contrução do conhecimento do professor a partir da formação continuada em ciências}

Desde muito cedo o ser humano busca por respostas para suas inquietações e questionamentos referentes à natureza e à sociedade, posto que o conhecimento estruturado modifica o próprio homem e suas relações. Assim, Chauí (2000) relata que [...] seja na criança, seja nos jovens ou nos adultos a busca da verdade está sempre ligada a uma decepção, a uma 
desilusão, a uma dúvida, a uma perplexidade, a uma insegurança ou, então, a um espanto e uma admiração diante de algo novo e insólito (CHAUí, 2000, p. 113).

Entretanto, o que é verdade para um pode não ser verdade para o outro. Isso ocorre entrelaçado com as visões de mundo, como diz Chauí (2000, p.113), pois “[...] há vários "mundos" e várias "sociedades" diferentes [...]" e tudo depende de onde vem a informação. Assim, a verdade tende a se transformar conforme as mudanças ocorridas no processo histórico, ou seja, conforme as concepções históricas: "Verdades não são arbitrárias nem causais ou acidentais, mas possuem causa e motivos que as explicam" (CHAUÍ, 2000, p. 133).

Outra questão a ser apresentada é a importância da linguagem na construção do conhecimento. O homem é um ser dotado de razão, como dizia Aristóteles, e as principais características humanas são a linguagem e a racionalidade. Percebe-se no homem a vontade de conhecer, explorar e investigar o mundo em que vive. Freire (2014, p. 108) ressalta muito bem quando destaca: Dizer a palavra não é privilégio de alguns homens, mas direito de todos os homens. Precisamente por isto, ninguém pode dizer a palavra verdadeira sozinho, ou dizêla para os outros, num ato de prescrição, com o qual rouba a palavra aos demais.

Assim, a linguagem é o principal instrumento de trabalho do professor e é a partir dela que ocorre todo o processo de ensino-aprendizagem. É a partir da linguagem que se tem retorno por parte do aluno, se conseguiu apropriar-se ou não do conhecimento. O professor consegue avaliar seu trabalho utilizando-se do que os alunos dizem durante os debates e discussões sobre o conteúdo ensinado. No caso dos alunos jovens e adultos, fica evidente a participação desses em sala de aula, quando debatem e argumentam com o professor. Assim, facilitam a avaliação docente, mesmo que o aluno não seja alfabetizado (FREIRE, 2014).

Pinto (2010) chama de "visão regressiva", pensar o aluno analfabeto como um sujeito que parou seu desenvolvimento. Não se trata de recuperar um crescimento que ficou estanque na infância. $\mathrm{O}$ adulto não pode ser visto como atrasado. É de suma importância ver o adulto como uma pessoa consciente, que trabalha, que frequenta igreja, grupos sociais, independente da apropriação da leitura e da escrita.

Para Chauí (2000), não somos apenas seres pensantes, mas também nos relacionamos e exprimimos nossos pensamentos e desejos e isso acontece a partir da linguagem, a qual tem papel fundamental na formação do professor. Stein (2010) explica que o homem é um ser racional, não somente por utilizar a linguagem como forma de comunicação, mas por conseguir utilizar a linguagem para transmitir conceitos de certo e errado ou mentiras e verdades, consegue fazer isso de maneira lógica e objetiva. Desta forma, com a linguagem, o homem é capaz de criar interações entre os sujeitos e percebe-se a forte influência dos meios sociais no desenvolvimento do homem. Esta mesma linguagem é utilizada na Formações Continuadas. 
A reflexão que Chauí (2000) traz, faz com que a prática pedagógica seja reorganizada e reavaliada, levando a novos encaminhamentos, que ajudam no processo da construção do conhecimento do docente e percebem como a sociedade contribui para o desenvolvimento da Ciência.

A sociedade e as Ciências estão interligadas, uma a mercê da outra, uma interfere no desenvolvimento da outra, assim, são transformadas e transformadoras. Para conhecer Ciências é preciso um grande esforço para entender as modificações constantes que ocorrem no meio e que essas interferem nos fenômenos, lembrando que o mundo está em constante modificação e é preciso "conceber os fenômenos naturais e os impactos que estes têm sobre nossa vida" (SASSERON, 2015, p. 52).

Portanto, ressalta-se a importância da Formação Continuada de Ciências pensada de forma que contribua para a construção do conhecimento do professor que atua na EJA. Compete também ao professor promover seu conhecimento e estar atento às atualizações que possam contribuir com sua prática, fazer análises de sua atuação como educador, examinar sua conduta e seu comportamento com objetivo de melhorar seu trabalho e ter consciência de que o realiza de forma correta (PINTO, 2010). O profissional da educação necessita de constantes avanços no seu currículo, visto que as mudanças ocorrem constantemente. Assim, [...] considera-se que a profissão docente requer permanente atualização, visto que a Ciência não é estática e sim dinâmica, estando em constante mudança” (BONZANINI; BASTOS, 2009, p.01).

\section{O que pensa o professor da eja quanto à formação continuada proposta pelo município de Cascavel/Pr}

A pesquisa teve como intuito buscar subsídios que auxiliem no estudo acerca da formação continuada de professores de ciências atuantes na EJA/Fase I e como esta formação interfere no planejamento para a sala aula. O campo de pesquisa foi a cidade de Cascavel, PR.

O município de Cascavel, PR, oferta a modalidade de Educação de Jovens e Adultos EJA, Fase I em onze escolas da Rede Pública Municipal de Educação e nelas funcionam vinte e uma turmas do regular, divididas por períodos ( $1^{\mathrm{o}}$ a $4^{\mathrm{o}}$ períodos) com vinte e um professores regentes. Assim, a pesquisa foi realizada com material coletado por professores dessas escolas via entrevistas áudio-gravadas e posteriormente transcritas. Dos vinte e um professores, dezoito foram entrevistados. Durante as entrevistas para a coleta de dados da pesquisa os professores levantaram algumas questões quanto à Formação Continuada para EJA, também a formação direcionada para a disciplina de Ciências bem como o que eles pensam sobre como podem contribuir para o seu desenvolvimento profissional e pessoal.

Cabe ressaltar que dos dezoito professores entrevistados, doze apresentam a Formação Inicial em Pedagogia. Para melhor visualização, as informações serão dispostas em 
Quadros. A seguir, o Quadro 01 menciona sobre a reflexão do professor em relação à Formação

Continuada para a EJA.

Quadro 01 - O que pensa o docente quanto à Formação Continuada para a EJA

\begin{tabular}{|c|c|}
\hline $\begin{array}{l}\text { Tema em } \\
\text { discussão }\end{array}$ & Citações relevantes \\
\hline $\begin{array}{l}\text { Temas de interesse } \\
\text { para estudo via } \\
\text { formação } \\
\text { continuada }\end{array}$ & $\begin{array}{l}\text { P1: olha... principal assim voltado para a alfabetização... } \\
\text { P7: ... bom! Acho que todos os temas são... todas as disciplinas são importantes } \\
\text { né... eu acho importantíssima a questão da Alfabetização; } \\
\text { P12: ai ai ... eu acho que principalmente a parte de Alfabetização; } \\
\text { P16: olha dentro da aprendizagem mesmo a questão da Alfabetização; } \\
\text { P17: olha ... eu gostaria ... principalmente a Alfabetização; } \\
\text { P18: Alfabetização; }\end{array}$ \\
\hline $\begin{array}{l}\text { Leituras sobre a EJA } \\
\text { já realizadas pelo } \\
\text { docente }\end{array}$ & $\begin{array}{l}\text { P14: sim... sempre nós realizamos leituras éh:: temos apostilas... é livros ou até } \\
\text { pedaços de livros... capítulos de livros... artigos referentes a isso. } \\
\text { P13: artigos científicos... livros né e faço algumas pesquisas na internet. No } \\
\text { entanto, tem que ter um filtro né que nem tudo que tá na internet a gente pode } \\
\text { aproveitar. } \\
\text { P12: principalmente os textos que as meninas disponibilizam né e o Currículo... } \\
\text { P10: sim do Currículo... artigo... } \\
\text { P8: Sobre a EJA, eu li artigos, li livros mais artigos assim que por causa da pós } \\
\text { P6: não } \\
\text { P4: ... sempre que nós fizemos leituras estudamos os textos sobre EJA } \\
\text { P2: ...livros... eu sempre procuro pesquisar livros que tragam sobre questões do } \\
\text { EJA... pesquisar sobre Paulo Freire } \\
\text { P1: olha voltado pra EJA... em revistas não mais eu vi em artigos né... a EJA tem } \\
\text { o Currículo próprio então }\end{array}$ \\
\hline $\begin{array}{l}\text { Necessidade do } \\
\text { professor para } \\
\text { melhorar a atuação } \\
\text { em Ciências na EJA }\end{array}$ & $\begin{array}{l}\text { P1: ah cursos né... } \\
\text { P5: é a formaçáo ((risos)) } \\
\text { P6: recursos né...eu acho } \\
\text { P8: eu penso assim... falta um material bacana pra gente né } \\
\text { P9: conhecimento científico } \\
\text { P10: alguns materiais... } \\
\text { P11: talvez mais materiais } \\
\text { P12: formação } \\
\text { P13: acho que mais cursos de formação. } \\
\text { P14: ...um preparo maior... mais cursos né... } \\
\text { P15: ah eu penso que a formação continuada. } \\
\text { P17: material didático } \\
\text { P18: material éh:: material físico suporte físico assim ah que seja laboratório. }\end{array}$ \\
\hline $\begin{array}{l}\text { Perfil de formação } \\
\text { continuada que o } \\
\text { professor considera } \\
\text { que poderia auxiliar } \\
\text { na atuação na } \\
\text { disciplina de ciências } \\
\text { da EJA }\end{array}$ & $\begin{array}{l}\text { P1: ... ah acho que se tivesse bastante já ajudava né. } \\
\text { P2: ... eu acho que pode ser dessa forma como estava sempre ocorrendo... } \\
\text { P5: eu acho que uma formação mais direcionada pra atividades que podem ser } \\
\text { desenvolvidas com os alunos adultos. } \\
\text { P8: então mais prática, uma elaboração de material ou alguma coisa assim. } \\
\text { P9: olha, que fugisse um pouco da teoria sabe? E que nos ensinasse mesmo a dar } \\
\text { aula de Ciências, sabe? } \\
\text { P11: eu acho que teriam que ser então experimentos voltados para adultos porque } \\
\text { essas formações continuadas são voltadas pra crianças e a Rede muitas vezes } \\
\text { esquece. } \\
\text { P12: eu acho que tem primeiro tem que ser voltada pra especificidade da EJA. } \\
\text { P13: eu acho que mais assim éh:. prática né... } \\
\text { P15: não normalmente é... então, as oficinas e os grupos menores então algumas } \\
\text { vezes foram ofertados por disciplina... } \\
\text { P17: olha, é o material mesmo que falta... }\end{array}$ \\
\hline
\end{tabular}

Fonte: dados da pesquisa (2017) 
Durante as entrevistas, os professores puderam falar sobre o tema abordado e relataram o que compreendem e qual a visão de cada um deles quanto à formação continuada ofertada pelo município de Cascavel/PR.

Os professores relataram sobre a importância da alfabetização no que se refere aos temas que gostariam que fossem tratados nos cursos de Formação Continuada no âmbito da EJA, e que, a partir da apropriação da leitura e a escrita, os alunos desenvolvem todas as disciplinas. Entretanto, este é um pensamento equivocado se considerarmos o que diz Freire (1996), quando cita que alfabetizar vai além de ensinar a ler e escrever, posto que o professor deve oportunizar o jovem e o adulto a viverem novas experiências, para que assim tenham uma visão crítica de mundo. Essa alfabetização ocorre com a superação do senso comum e a partir da interação entre as atividades escolares e cotidianas, as quais a escola explora para alfabetizar e formar o sujeito crítico (MUENCHEN; AULER, 2017).

Quanto à questão que aborda as leituras para o desenvolvimento do professor, percebe-se que os professores leem muito pouco e se limitam a ler o que a coordenação determina ou então textos que são necessários para algum curso que estejam realizando. Dessa forma, o hábito pela busca de informações referentes à EJA ou às Ciências aparece raras vezes nas entrevistas, demonstrando que poucos professores esboçam esta necessidade. Deste modo, percebe-se a necessidade destes professores criarem hábitos de leitura e estudo para que avancem no seu desenvolvimento profissional e pessoal.

Segundo Gadotti (2000), o professor precisa estudar sobre a EJA, aprofundar os conhecimentos sobre o tema, conhecer, entender a partir de leitura e do contato direto com os alunos, pois "Ler sobre a educação de adultos não é suficiente" (GADOTTI, 2000, p.32). Portanto, é preciso que este professor esteja envolvido com seus pares em grupos de estudos organizados pela escola ou nos momentos de hora atividade, para que as leituras sejam interpretadas e discutidas e contribuam de alguma maneira no trabalho.

O trabalho em grupo é fundamental. A colaboração entre pares permite maior possibilidade de o professor ver nos outros as mesmas dificuldades que ele tem e isso traz efeitos positivos. $\mathrm{O}$ apoio fornecido pelo grupo fomenta tanto o desenvolvimento cognitivo quanto o afetivo, especialmente este último (CUNHA; KRASILCHICK, 2000, p. 10).

Outra pergunta da entrevista foi a questão relacionada à falta para melhorar a atuação na disciplina de Ciências na EJA. Os professores, na sua maioria, relataram que a formação continuada é um dos quesitos essenciais para o crescimento profissional e pessoal e que os materiais podem interferir no desenvolvimento das aulas sendo estes também de suma importância. Um dos professores citou o laboratório como uma necessidade, deste modo, constata-se que o professor apresenta interesse em melhorar seu desenvolvimento em sala de aula e que almeja uma formação de maior qualidade. Segundo Cunha e Krasilchik (2000), as 
formações continuadas não têm tido uma sequência, e isso tem sido um obstáculo para a obtenção de resultados positivos. Estas formações, como são ofertadas, não trazem mudanças para a escola nem para a sala de aula. "É preciso substituir as propostas isoladas, fragmentadas e esporádicas por cursos que tenham continuidade e acompanhamento" (CUNHA; KRASILCHIK, 2000, p. 10). Segundo as autoras, é preciso um tempo maior para que as mudanças ocorram, com projetos organizados e que sejam distribuídos durante o ano todo.

Outro questionamento foi em relação ao tipo de formação continuada que o professor considera que poderia auxiliar na sua atuação na disciplina de Ciências da EJA. Os docentes relataram que, da maneira como a Formação vem sendo ofertada não é ruim, apenas é necessário que seja realmente continuada, já que por vezes as formações ocorrem em um dia e posteriormente não há continuidade.

Outra questão destacada foi o fato de ter poucos momentos de formação em Ciências para a EJA e que muitas vezes os professores de EJA são encaminhados para cursos de formação direcionados para crianças, fator preocupante, visto que o trabalho com jovens e adultos não deve ser infantilizado. Para Pinto (2010), é um equívoco achar que os jovens e adultos sejam "atrasados" ou comparados com crianças. Precisamos ver o adulto como um sabedor, um sujeito que trabalha, convive socialmente e que seu desenvolvimento intelectual não para, mesmo sendo analfabeto.

Os entrevistados também discorreram sobre a estrutura dos cursos e indicaram que os cursos são muito teóricos e que gostariam que fossem mais práticos e tratassem de novos aspectos sociais e culturais: “[...] o saber é considerado como resultado de uma produção social, sujeito a revisões e reavaliações, fruto de uma interação entre sujeitos [...]” (NUNES, 2001, p. 34). A teoria é, necessariamente, elaborada com assuntos gerais ou filosóficos, portanto, cabe levar o professor, durante os momentos de formação, a explorar já que a teoria exige que o professor atue sobre ela, para traduzir, avaliar e transformar. Assim, a teoria fará sentido e ganhará vida. Não há prática sem teoria ou teoria sem prática (FREIRE, 2014; SÁNCHEZ VÁZQUEZ, 2007; TARDIF, 2002).

Assim, percebe-se que o professor almeja uma formação continuada de qualidade, com uma sequência, que propicie construção do conhecimento do professor, e encaminhamentos que amparem o que o trabalho do professor exige.

\section{Considerações finais}

Percebe-se a necessidade da Formação Continuada em Ciências ao se analisar o contexto apresentado, principalmente àqueles que irão trabalhar com outras modalidades de ensino como a EJA, pouco discutida nos cursos de formação inicial.

A Formação Continuada de Ciências para o professor da EJA tem potencial para estabelecer encaminhamentos, direcionar o trabalho bem como levar o professor a construir o 
seu conhecimento e a refletir acerca das questões epistemológicas essenciais para o entendimento do processo de produção da Ciência.

A formação não pode ser pontual, mas permanente, e integrar aspectos de conhecimento de conteúdos, das práticas escolares e das relações sociais. Neste panorama, a sala de aula é considerada um espaço dinâmico de vivência e construção de conhecimento, e a relação entre professor e alunos pode favorecer o aprendizado.

Desta forma, é preciso estimular a reflexão, no âmbito da gestão da educação, acerca de qual tipo de Formação Continuada se almeja, e qual tipo de conhecimento se quer construir com o professor. Neste sentido, vale considerar os apontamentos de Tardif (2002), os quais indicam que o professor é um sujeito que necessita possuir certos conhecimentos relativos à ciência da educação, à pedagogia e a epistemologia que contribua para a construção do seu conhecimento.

Entendendo a relevância da Formação Continuada e sua associação com o desenvolvimento do professor quanto à construção do seu conhecimento, percebe-se a necessidade de superação de modelos cristalizados que ainda imperam na Formação Continuada.

\section{Referências}

BASTOS, F. A pesquisa em educação em ciências e a formação de professores. Ciência e Educação, Bauru, v. 23, n. 2, p. 299-302, 2017.

BONZANINI, T. K.; BASTOS, F. Formação continuada de professores: algumas reflexões. In: Encontro Nacional de Pesquisa em Educação em Ciências, 7, 2009, Florianópolis. Anais ... Encontro Nacional de Pesquisadores em Educação em Ciências. Belo Horizonte: ABRAPEC, 2009.

BRASIL. MINISTÉRIO DA EDUCAÇÃO. Trabalhando com jovens e adultos: a sala de aula como espaço de vivência e aprendizagem. MEC, Brasília, 2006. Disponível em: $<$ http://portal.mec.gov.br/secad/arquivos/pdf/eja_caderno2.pdf>. Acesso em: 01 ago. 2017.

MINISTÉRIO DA EDUCAÇÃO. FUNDEB. Disponível em: <http://portal.mec.gov.br/ fundeb-sp-1090794249>. Acesso em: o6 jul. 2017. . Ministério da Educação. Resolução CNE/CP No 1/2oo6, de 15 de maio de 2006. Institui Diretrizes Curriculares Nacionais para o Curso de Graduação em Pedagogia, licenciatura. Brasília: Conselho Nacional de Educação - Conselho Pleno, 2006. Acesso em 14-08-2017

CHAUÍ, M. Convite à Filosofia. São Paulo: Ed. Ática, São Paulo, 2000.

CUNHA, A. M. de O.; KRASILCHIK, M. A formação continuada de professores de ciências: percepções a partir de uma experiência. Anais... Caxambu: ANDEP, 2000. 
FLICK, U. Introdução à pesquisa qualitativa. Tradução Joice Elias Costa. $3^{\mathrm{a}}$ ed. Porto Alegre: Artmed, 2009, p.205.

FREIRE, P. Pedagogia do oprimido. $57^{\mathrm{a}}$ ed. Rio de Janeiro: Paz e Terra, 2014.

GADOTTI, M. Educação de Jovens e Adultos correntes e Tendências. 2000. (29-39 p.). In: GADOTTI, m.; ROMÃO, J. E. (Orgs.) $-2^{\text {a }}$ ed. São Paulo: Cortez: Instituto Paulo Freire, 2000.

GATTI, B. A. Formação de professores no Brasil: características e problemas. Educação \& Sociedade, Campinas, n.31, 2010.

GATTI, B. A.; SÁ BARRETO, E. S. Professores do Brasil: impasses e desafios. Brasília: UNESCO, 2009.

GIMENES, C. I - Um estudo sobre epistemologia da formação de professores de Ciências: indícios da constituição de identidades. Dissertação (Mestrado em Ciências Sociais) - Universidade Estadual de Maringá, Maringá Curitiba, 2011.

GIOVINAZZO J., C. A. A formação profissional nos cursos de licenciatura e o exercício do magistério na educação básica: intenções, realizações e ambiguidades. Educar em Revista, $\mathrm{n}^{\mathrm{o}}$. spe.1, p.51-68, 2017.

KRASILCHIK, M. O professor e o currículo das ciências. São Paulo: EPU/EDUSP, 1987. MARASCHIN, M. S.; BELLHOCHIO, C. R. Uma proposta colaborativa de formação de professores na Educação de jovens e adultos. Revista do Centro de Educação UFSM. v. 31, n. 2, jul./dez. 2006

MUENCHEN, C.; AULER, D. Abordagem temática: desafios na educação de jovens e adultos.

Revista Brasileira de Pesquisa em Educação em Ciências. v. 7, n. 3, 2017.

NUNES, C. M. F. Saberes Docentes e Formação de Professores: um Breve Panorama da Pesquisa Brasileira. Educação \& Sociedade, ano XXII, n. 74, Abril/2001.

PINTO, A. V. Sete Lições sobre educação de adultos. $16^{\mathrm{a}}$ ed. São Paulo: Cortez, 2010.

SÁNCHEZ VÁZQUEZ, A. Filosofa da práxis. Buenos Aires: CLACSO; São Paulo: Expressão Popular, 2007.

SASSERON, L. H. Alfabetização científica, ensino por investigação e argumentação: Relações entre ciências da natureza e escola. Revista Ensaio, Belo Horizonte, v. 17 n. especial, p. 49-67, 2015 .

SOARES, L. J. G.; PEDROSO, A. P. F. Formação de Educadores na educação de Jovens e Adultos (EJA): Alinhavando e tecendo possibilidades. Educação em Revista, Belo Horizonte, v. 32, n. 04, p. 251-268, 2016.

STEIN, E. Aproximações sobre Hermenêutica. $2^{\text {a }}$ ed. Porto Alegre: EDIPUCRS - Editora Universitária da PUCRS, 2010.

TARDIF, M. Saberes docentes e formação profissional. Petrópolis, Rio de Janeiro: Vozes, 2002. 


\section{Biografia Resumida}

Jaqueline Miliavaca Wielewski: Mestre em Educação em Ciências pelo Programa de Pós-graduação em Educação em Ciências e Educação Matemática - PPGECEM - mestrado e doutorado, pela Universidade Estadual do Oeste do Paraná (UNIOESTE). Especialização na Área de Educação, com concentração em Educação Especial pela Faculdade Internacional de Curitiba (FACINTER) e Especialização em Educação Especial - Formação Continuada de Professores para Atendimento Educacional Especializado - AEE pela Universidade Federal do Ceará (UFC). Graduação em Pedagogia pela UNIOESTE. Docente da rede pública estadual do Paraná com experiência na Educação Infantil, Ensino Fundamental, Ensino Médio e na modalidade de Educação Especial.

Lattes: http://lattes.cnpq.br/7817902273933577

Contato: jaquelinemiliavaca@gmail.com

Dulce Maria Strieder: Doutorado em Educação pela Universidade de São Paulo. Mestrado em Educação pela Universidade Federal de Santa Maria e graduação em Física pela mesma Universidade. Atualmente é professora associada da Universidade Estadual do Oeste do Paraná, com atuação na área de Física e no Programa de Pós-Graduação em Educação em Ciências e Educação Matemática (Mestrado e Doutorado) do Centro de Ciências Exatas e Tecnológicas/UNIOESTE. Tem experiência na área de Ensino de Ciências, atuando principalmente nos seguintes temas: formação de professores, cultura científica e ensino de fisica.

Lattes: http://lattes.cnpq.br/4981747301070724

Contato:dulce.strieder@unioeste.br 